\title{
SENADO BRASILEIRO: CASA FEDERATIVA OU PARTIDÁRIA?*
}

\section{Pedro Robson Pereira Neiva Márcia Miranda Soares}

\section{Introdução}

Apesar de as câmaras altas ainda serem bem menos conhecidas do que as câmaras baixas, os estudos a seu respeito, bem como sobre o bicameralismo, aumentaram substancialmente nos últimos anos. Em obra que já se tornou clássica, Tsebelis e Money (1997) fazem uma discussão sobre o desenvolvimento histórico da instituição e sobre as diferentes formas de resolução de conflitos entre as duas casas legislativas. Em outra referência importante, Lijphart (1999) classifica os sistemas bicamerais a partir de dois conceitos que refletem as diferenças e semelhanças entre elas: o primeiro,

* Agradecemos o apoio de Andrea Freitas, de Júlio Costa e de Maurício Izumi na montagem do banco de dados que deu origem à essa pesquisa.

Artigo recebido em 13/04/2011

Aprovado em 28/12/2012 chamado de "simetria", diz respeito à equivalência de poderes entre as duas câmaras; o segundo, chamado de "congruência", refere-se à similaridade em suas composiçôes. Outro trabalho relevante foi elaborado por Heller (1997), no qual o autor avalia o impacto das instituições bicamerais sobre o controle orçamentário em diversos países europeus.

À semelhança do que aconteceu em nível mundial, os estudos sobre o bicameralismo e sobre o Senado brasileiros também aumentaram. A produção sobre o tema já é bastante ampla e diversificada, conforme se observa nos seguintes exemplos: representação feminina (Bohn, 2007; Neiva, 2008); perfil de senadores (Lemos e Ranincheski, 2003; Neiva e Izumi, 2012a); dinâmica intercameral (Vilarouca, 2006; Hiroi, 2008; Inácio e Araújo, 2011; Neiva, 2011 a e b); disciplina e coesão partidária (Desposato, 2004; Arretche, 2011; Neiva, 2011b); proposições e produção legislativas (Araújo, 2008; Ricci, 2008); atribuições exclusivas (Loureiro, 2001; 
Lemos e Llanos, 2007). No que diz respeito à dimensão federativa, foco principal desse artigo, cabe mencionar os trabalhos de Backes (1999), Desposato (2004) e Branco (2008).

Uma discussão importante nos estudos sobre o tema tem sido o da sua relação com o federalismo. Existe uma tese bastante estabelecida de que este último está fortemente relacionado com o bicameralismo (Anckar, 1999; Lijphart, 1999; Massicotte, 2001; Patterson e Mughan, 2001; Stepan, 2001; Tsebelis e Money, 1997). Paralelamente, acredita-se que as câmaras altas representam os interesses subnacionais (de estados, províncias, cantões, regiões ou comunidades autônomas) no processo decisório no nível nacional (Russell, 2001; Swenden, 2011). De fato, a relação entre as duas variáveis é bem antiga; nasceu durante o processo de consolidação da independência dos Estados Unidos, quando os estados menores apresentaram a demanda de que a sua representação no Senado fosse igual à dos estados maiores, como exigência para aderir à nova federação que se formava. Tal arranjo institucional espalhou-se pelo mundo e parece ainda obedecer à sua justificativa inicial, haja vista que 19 dos 25 países atualmente federativos são também bicamerais.

Não há como dizer que a relação entre as duas variáveis não é expressiva, como mostra a literatura e reforçam os números. Porém, ela não é absoluta, nem inquestionável. Vale lembrar que 6 dentre 25 países federativos são unicamerais e que 49 dos 78 países bicamerais são unitários. ${ }^{1}$ Esses números mostram que o federalismo está muito mais para uma condição suficiente - ainda que não exaustiva do que necessária para a existência de uma câmara alta. É preciso lembrar, ainda, que a diversidade entre as câmaras altas é imensa, bem maior do que a encontrada entre as câmaras baixas (Neiva, 2006; Tsebelis e Money, 1997). Tampouco são os arranjos federativos similares entre si (Souza, 1998).

Pesquisas recentes revelam algumas peculiaridades entre os sistemas bicamerais na América Latina: além de serem altamente simétricos - isto é, contarem com câmaras altas com poderes equivalentes aos das câmaras baixas -, convivem com o sistema presidencialista, uma característica que pode ser tão ou mais importante do que o federalismo para explicar a existência e os poderes das câmaras altas (Llanos e Nolte, 2003; Neiva, 2006; Swenden, 2011). Acreditamos que estudos específicos de países da região podem contribuir para aprofundar o conhecimento sobre o funcionamento e a interação entre essas instituiçôes. Afinal, foi o local onde o presidencialismo, o bicameralismo e o federalismo de matriz norte-americana mais proliferaram.

Este artigo pretende dar uma contribuição para esse debate, a partir do estudo do caso brasileiro e de uma questão específica. Procuramos avaliar o relacionamento entre os titulares dos executivos estaduais com os representantes oficiais dos estados no Congresso Nacional. Em outras palavras, procuramos identificar as variáveis que explicam o comportamento dos senadores no plenário do Senado, especialmente se eles recebem algum tipo de influência dos governadores de seus respectivos estados. $\mathrm{Ou}$ ainda: avaliamos se os senadores obedecem mais à orientação de seus respectivos partidos ou aos ditames dos governadores das unidades federativas de onde provêm, seja em matérias de cunho geral, seja nas de caráter federativo.

Essa discussão vem sendo realizada há algum tempo pela ciência política brasileira e já se encontra razoavelmente amadurecida. Parte da literatura considera que os governadores são atores muito poderosos no nosso sistema político, capazes de influenciar não apenas as eleições e as políticas local e regional, mas também a própria atuação das bancadas estaduais de parlamentares federais (Abrucio, 1998; Desposato, 2004). Com isso, forçam o governo federal a negociar com eles a elaboração de políticas públicas nacionais (Souza, 1998). Por outro lado, Cheibub, Figueiredo e Limongi (2009) não encontraram evidências de que os governadores exercem mais pressão do que os partidos políticos sobre a atuação dos legisladores. Segundo eles, o sistema oferece mecanismos que permitem ao governo central evitar ou neutralizar as tendências dispersivas do arcabouço institucional, codificado pela Constituição de 1988. O problema é que tais estudos se dedicaram à situação dos deputados, exclusivamente. Ainda não sabemos como se dá a relação com os senadores.

O estudo do caso brasileiro parece ser especialmente interessante, por diversos motivos. Em 
primeiro lugar, por causa da complexidade do país, com suas enormes disparidades regionais, geográficas, econômicas e sociais, que acabam se refletindo no ambiente político. Um segundo motivo é que ele possui uma câmara alta com extrema força política: além de contar com todas as prerrogativas exercidas pela câmara baixa, responde por doze atribuiçōes exclusivas (Stepan, 1999). Uma terceira justificativa deve-se ao fato de que se trata de um senado com características fortemente federativas, as quais se expressam de diversas formas: pela representação paritária dos estados - a qual promove altíssima desproporcionalidade de representação -, pela grande presença de ex-governadores, pela prerrogativa de autorizar o endividamento de estados e municípios, pela participação que teve no processo de ajuste fiscal empreendido no país nos últimos anos.

Para realizar a pesquisa, utilizamos um banco de dados criado recentemente, composto pelas votaçóes nominais realizadas no Senado nos vinte anos posteriores à redemocratização do país. Nesse período, a dimensão federativa tornou-se especialmente importante, culminando com o aumento das transferências de recursos financeiros, fiscais e políticos da União para os estados e os municípios. Prevaleceu durante a Assembleia Nacional Constituinte a ideia de que, quanto mais poder e direitos fossem concedidos para as subunidades federativas, mais democrático seria o Brasil. Cabe destacar também o fato de os governadores terem sido os protagonistas principais do processo de transição democrática (Palermo, 2000). Afinal, eles voltaram a ser eleitos diretamente já em 1982, sete anos antes da primeira eleição direta para presidente da República. Naquela ocasião, a oposição venceu em dez estados, incluindo os três maiores: São Paulo, Minas Gerais e Rio de Janerio. Isso lhes deu grande ascendência moral e política sobre os trabalhos da Constituinte.

O artigo está estruturado da seguinte forma: na seção que se segue, fazemos uma retrospectiva da discussão sobre o relacionamento entre os poderes Executivo e Legislativo no plano nacional, enfatizando a tese da influência dos governadores estaduais. Em seguida, na terceira seção, apresentamos nosso modelo estatístico para explicar o comportamento dos senadores em relação às preferên- cias dos presidentes e dos governadores. Na quarta seção, analisamos as evidências empíricas encontradas, procurando identificar o impacto dos partidos e dos governadores sobre as respectivas bancadas estaduais de senadores. Por fim, apresentamos nossas considerações finais.

\section{A relação Executivo/Legislativo e a interferência dos governadores}

A discussão sobre o relacionamento entre o Executivo e o Legislativo tem estado no centro da agenda da ciência política brasileira há mais de duas décadas. Basicamente, ela gira em torno da concentração/dispersão do poder governamental para tomar decisões. Trata-se de saber que atores dispõem de que poder e em virtude de que regras. Desde o início, a natureza fragmentada do sistema partidário, o regime presidencialista e a organização federativa aparecem como elementos fundamentais do jogo institucional, influenciando fortemente o desempenho governamental (Palermo, 2000).

Nesse período, apareceram duas correntes principais, que promoveram um debate intenso $\mathrm{e}$ frutífero. De um lado, estão os autores que identificam nas regras eleitorais a origem de muitas mazelas do sistema político brasileiro. Para eles, o sistema proporcional de lista aberta promove a fragmentação partidária e uma relação personalista dos eleitores com seus representantes, gerando vínculos fracos entre os candidatos e seus respectivos partidos. Segundo tais autores, isso geraria consequências nefastas no âmbito do Legislativo, tais como baixas coesão e disciplina partidária (Ames 2003; Mainwaring e Pérez Liñan, 1997; Mainwaring e Shugart, 1997).

Ainda segundo essa corrente, a situação ficaria mais grave quando essas características são combinadas com outros aspectos institucionais do sistema político nacional. A fragmentação partidária teria seus efeitos ampliados quando combinada com o sistema presidencialista, em que o partido do presidente ocupa uma pequena fração das cadeiras no Legislativo. A consequência inevitável seria a incapacidade do presidente para construir uma base parlamentar estável, consistente e duradoura, 
ficando sujeito à formação de maiorias a cada votação. Tudo isso levaria a um sistema caótico, envolto em crises frequentes entre os poderes Legislativo e Executivo e paralisia decisória (Abranches, 1988; Mainwaring, 2001; Ames, 2003).

A dimensão federativa aparece como um desdobramento dessa discussão. Segundo alguns autores, os governadores teriam uma força política extraordinária, capaz de definir as decisões que são tomadas no nível federal, chegando a se transformar em um "quarto poder da República" (Samuels e Abrucio, 2000). Isso aconteceria porque eles contam com poderes e recursos importantes para influenciar os parlamentares federais, especialmente aqueles que podem otimizar a sua performance eleitoral: recursos clientelísticos e de campanha e influência sobre lideranças políticas locais, como prefeitos e deputados estaduais, que funcionam como seus cabos eleitorais. Além disso, afirmam os autores, associar-se a uma candidatura a governador, a "locomotiva" da eleição legislativa, seria essencial para o êxito eleitoral do parlamentar federal (Abrucio 1998; Samuels 2003; Willis, Garman e Haggard, 1999).

$\mathrm{Na}$ visão desses autores, a consequência disso seria um modelo federativo "estadualista", com presidentes fracos, incapazes de construir uma coalizão governamental estável e duradoura e de implementar reformas importantes para o desenvolvimento político e econômico do país. A ideia é de que, mesmo depois de eleitos, os parlamentares federais continuariam obedientes aos interesses dos governadores, obrigando o presidente a negociar com cada um deles, e não centralizadamente com os partidos políticos (Samuels, 2003, 2008; Souza, 1998; Desposatto, 2004). Affonso (1994) chegou a dizer que "o Congresso Nacional funcionava como uma 'Câmara Nacional de Vereadores”" e Abrucio (1998), que "a Câmara dos Deputados é composta por vinte e sete 'bancadas de estados', que são independentes dos partidos políticos". Ao serem indagados sobre como decidiam quando havia conflito entre a necessidade dos seus estados e as posiçôes dos seus partidos, $60 \%$ dos parlamentares responderam que tendiam a responder aos interesses regionais e apenas 31\% disseram que obedeciam à legenda partidária (Mainwaring, 2001).
Em uma abordagem diferente, mas que chega a conclusóes parecidas, Stepan (2000) faz uma análise comparada das federações no que diz respeito ao aspecto democrático. $\mathrm{O}$ autor conclui que o Brasil é um caso paradigmático de constrangimento ao poder da maioria (demos constraining), ao possibilitar que minorias, provenientes de estados menores, possam bloquear as políticas nacionais. Tal situação seria decorrente da grande desigualdade na ocupação do território nacional e da regra constitucional de que cada unidade da federação deve ter o número fixo de três senadores, independentemente do tamanho do seu território ou da sua população. Tal mecanismo faz com que a nossa câmara alta seja umas das mais desproporcionais do mundo ( $\mathrm{Sa}$ muels e Snyder, 2001; Stepan, 2000). No Senado, o voto de um cidadão de estados pequenos como Roraima, Rondônia, Amapá e Tocantins (para citar só alguns) tem um peso muito maior do que o de um cidadão de estados maiores, como Minas Gerais, Rio de Janeiro e São Paulo, principalmente. No limite, Stepan (2000) mostra que uma minoria dos estados do Norte, do Centro-Oeste e do Nordeste poderia bloquear os interesses de uma maioria composta pelos estados desenvolvidos das regiôes Sul e Sudeste, sub-representadas em ambas as casas legislativas, especialmente na câmara alta. Isso porque, embora contassem com apenas $43 \%$ da população, os primeiros obtiveram $74 \%$ das cadeiras no Senado em 1990. De acordo com Stepan, a situação torna-se mais crítica em um contexto no qual prevalecem partidos voláteis, pouco coesos, indisciplinados e imprevisíveis. ${ }^{2}$

No entanto, apesar da força dos governadores e das perspectivas catastróficas apontadas por essa literatura, o que observamos não foi uma paralisia decisória, com agravamento da crise econômica e instabilidade da democracia. Pelo contrário, o país foi capaz de implementar um plano de estabilização da moeda, acabou com a hiperinflação, promoveu ajustes fiscais e realizou uma série de mudanças que alteraram o status quo federativo em favor do governo central, algo impensável para os defensores do federalismo estadualista. E isto foi possível porque os presidentes do período pós-autoritário não encontraram barreiras intransponíveis no Congresso e conseguiram aprovar boa parte de suas propostas. 
A inflação foi controlada, bancos estaduais foram privatizados, ${ }^{3}$ os estados renegociaram suas dívidas com a União, passando a comprometer seus recursos com o pagamento dela. Além disso, a Lei de Responsabilidade Fiscal estabeleceu limitações nos gastos com pessoal e normas rígidas contra o endividamento desenfreado dos governos estaduais.

Esses resultados contrariam as previsões da corrente da literatura que previa ingovernabilidade quase catastrófica no país, a qual prevaleceu na primeira metade da década de 1990; por outro lado, reforça a corrente a que a ela se opóe, que ganhou força a partir de meados dos anos de 1990. Com base em dados empíricos sobre o comportamento legislativo na Câmara dos Deputados, esta mostrou um quadro muito diferente da suposta fragilidade dos partidos, da fraqueza do presidente e do Legislativo como empecilho para a governabilidade e causa do fracasso inevitável do sistema político. Essa corrente assinalou que o presidente teve grau de sucesso considerável na implementação da sua agenda, a maioria das leis aprovadas foi proposta pelo Executivo federal e o índice de aprovação dos seus projetos foi bastante alto. E mais, os partidos apresentaram razoável grau de disciplina e o presidente contou com o suporte dos partidos que faziam parte da sua base, governando com a ajuda de uma coalizão de legendas ideologicamente consistentes (Figueiredo e Limongi, 1999, 2000; Meneguello, 1998).

Segundo Figueiredo e Limongi, a despeito dos incentivos advindos da arena eleitoral, da predominância do voto pessoal e da incapacidade dos partidos de controlarem as candidaturas, as lideranças partidárias e o presidente possuem recursos capazes de garantir a disciplina no plenário da Câmara dos Deputados. Especificamente, variáveis institucionais - os poderes legislativos do presidente ${ }^{4} \mathrm{e}$ a organização centralizada dos trabalhos do Congresso permitem que o Executivo controle a agenda e negocie com os líderes dos partidos. Para ter alguma capacidade de pressão na negociação com o Executivo, não restaria ao parlamentar individual outra alternativa que não fosse a de seguir as orientaçōes partidárias.

No que diz respeito à pressão regional, Cheibub, Figueiredo e Limongi (2002) verificaram que o fato de os governadores serem ou não aliados do presidente não tem um efeito importante sobre a distribuição dos recursos federais aos estados. Segundo os autores, a variável efetivamente relevante nesse sentido é a que indica se o governador pertence ou não à coalizão governamental. Em trabalho posterior, Cheibub, Figueiredo e Limongi (2009) reforçam essa posição ao identificarem que não existe diferença relevante no apoio às proposições legislativas do governo federal entre deputados provenientes de estados nos quais o partido do governador participa do gabinete e aqueles em que o governador pertence a um partido de oposição. Em outras palavras, apesar de concordarem que os governadores são atores políticos importantes, os autores não acreditam que o seu poder institucional seja suficiente para eliminar a influência dos fatores partidários.

$\mathrm{Na}$ mesma linha, outros autores chegaram a conclusōes semelhantes. Arretche (2002) verificou que os governos subnacionais não representam um ponto de veto intransponível à implementação da agenda de reformas do governo federal. Pereira e Rennó (2001) descobriram que fazer parte da mesma coligação do governador do estado não ajuda o candidato a se reeleger. Soares (2007) apontou a influência limitada dos governadores na eleição para deputado federal, desqualificando-os como "locomotivas" das eleiçóes parlamentares. Deposato (2004) chegou à conclusão que o comportamento dos legisladores deve ser explicado por atores nacionais - o presidente e os partidos nacionais -, sugerindo que o sistema partidário se estabilizou e que os legisladores estão imunizados contra as influências provenientes dos estados. Arretche e Rodden (2004) verificaram que o presidente, de fato, tem uma relação importante com os estados, para os quais transfere uma quantidade expressiva de recursos; no entanto, ele faz isso para os estados que contam com maior número de parlamentares na sua coalizão. Soares e Neiva (2011), ao analisarem as transferências voluntárias da União aos estados, apontaram que o alinhamento partidário dos governadores com o presidente, a sobre-representação política no Legislativo nacional e critérios redistributivos tendem a aumentar o volume de recursos discricionários que os governos estaduais recebem da União. 
Atualmente, já não existe mais a expectativa de um inevitável fracasso do sistema político brasileiro e poucos defenderiam o argumento de que a força dos governadores estende-se para o Legislativo. Porém, as explicações que foram dadas servem para a câmara baixa, exclusivamente. Mas o que dizer da câmara alta, casa federativa por excelência? Não deveríamos esperar que seu comportamento fosse muito distinto, por diversos motivos? Em primeiro lugar, porque as funções e as atribuições das duas casas não são as mesmas: com exceção da prerrogativa de iniciar a apreciação dos projetos de lei do Executivo, o Senado conta com todas as atribuiçōes que tem a Câmara dos Deputados, além de várias outras competências privativas. Em segundo lugar, porque elas diferem também nas suas estruturas e regras internas, no grau de centralização, na forma como se organizam e como decidem. Um terceiro motivo diz respeito aos próprios perfis dos deputados e senadores: esses últimos estão num patamar superior da carreira política, muitos foram ex-governadores e/ou são pretendentes ao cargo. Ainda que muitos governadores sejam a principal liderança política no Estado, não podem se candidatar à reeleição quando estão no segundo mandato, restando-lhes poucas opções a não ser o Senado. Conforme mostra Izumi (2010), dos 219 senadores titulares, eleitos no período 1988 a 2006, 31,5\% já tinham sido governadores. Dos 27 governadores atuais, 30\% deles já ocuparam o cargo de senador. A partir de levantamento próprio, verificamos que nada menos que 61\% (19 em 31) dos presidentes não interinos da nossa história republicana passaram pelo cargo de senador, antes ou depois do mandato. Se considerarmos apenas os que foram eleitos - isto é, excluindo os militares não eleitos esse número sobe para 75\% (21 em 27).

Se parte da literatura em ciência política nega a tese segundo a qual o comportamento dos deputados individuais seja moldado e ditado pelo poder dos governadores, em contraposição aos partidos e ao Executivo federal (Cheibub, Figueiredo e Limongi, 2009), também há trabalhos que apontam perspectiva similar para o Senado, destacando seu papel especial em alguns dos pontos centrais da agenda governamental: no ajuste fiscal, no controle da inflação, na estabilização da economia (Lourei- ro, 2001; Loureiro e Abrucio, 2004). E o Senado fez isso criando instrumentos para disciplinar comportamentos irresponsáveis de prefeitos e governadores, acostumados à desorganização econômica. Ainda que fosse sensível a pressões políticas vindas dos governos estaduais, a Casa impôs a eles restrições de gastos e implementou açôes importantes de caráter moralizador. ${ }^{5}$ Conforme apontam Loureiro (2001) e Abrucio e Loureiro (2004), a maioria dos senadores optou por uma nova "cultura de responsabilidade fiscal". E isso foi feito de forma negociada, e sem submissão ao poder Executivo, já que fazia parte da agenda do Senado.

Para ilustrar o seu argumento, Abrucio e Loureiro citam dois exemplos que merecem ser reproduzidos. Um deles foi a delegação de poderes ao Banco Central, facultando-lhe não mais encaminhar ao Senado pedido de autorização de endividamento dos governos estaduais com resultado primário negativo. A despeito da pressão vinda dos governadores, os senadores "amarraram as próprias mãos", dando ao Banco Central capacidade para emitir parecer conclusivo e de rejeitar os pedidos que não preenchessem as condições legais. Dessa forma, criaram um mecanismo para evitar pressões "irrecusáveis", ao mesmo tempo em que atenderam as necessidades de controle do endividamento (Loureiro, 2001).

Outro exemplo é o das normas produzidas no Senado que serviram de base para a Lei de Responsabilidade Fiscal (LRF), tida como marco no ajuste fiscal do país. No intuito de evitar gastos imoderados, estabelecer uma administração prudente e oferecer amplo acesso de informaçôes sobre as contas públicas, a LRF criou puniçôes de natureza política, jurídica e administrativa para os governantes que a desrespeitassem (Loureiro e Abrucio, 2004).

Portanto, uma análise que avalie o padrão de relacionamento dos governadores com os deputados federais - e suas possíveis consequências sobre o relacionamento com o Executivo federal - não deveria estender suas conclusóes para todo o Legislativo. Ainda que a influência dos governadores sobre o sistema político brasileiro fosse incontestável, ela provavelmente não seria a mesma sobre deputados e senadores. Esse artigo procura contribuir para o avanço dessa literatura exatamente nesse ponto: 
procurando incluir o Senado na discussão. Afinal, trata-se da casa legislativa que representa as unidades da federação, conforme diz o texto constitucional. Entre outras, tem a prerrogativa de autorizar o endividamento externo dos entes federativos, sendo a única câmara alta no mundo que possui tal atribuição. Há que se considerar, ainda, o fato de que seus poderes não se limitam aos assuntos federativos e que ele conta com atribuiçōes exclusivas, relacionadas com a "questōes de Estado", nas áreas de políticas externa e de defesa e que envolvem o equilíbrio geral do sistema político (Neiva, 2006).

Além disso, o Senado brasileiro destaca-se como um dos mais desproporcionais do mundo, em termos de representação distrital, só ficando atrás do Senado argentino. É possível que tal desproporcionalidade influencie o seu funcionamento, já que ela está associada a outras características que marcam as diferenças regionais no país. Os autores que trabalham com essa perspectiva afirmam que as regiōes menos desenvolvidas estão impregnadas pela "política do atraso", por valores paroquiais, particularistas, clientelistas e patrimonialistas (Avelar e Walter, 2008; Carvalho, 2009; Mainwaring, 2001; Soares, 2001; Souza, 1976). Segundo tais autores, encontram-se nessas regiōes cidadãos menos informados, partidos tradicionais e políticos interessados basicamente em obtenção de recursos para suas localidades carentes. A conclusão que chegam é que a negociação com o poder central é feita com base em acordos pontuais e transferências governamentais discricionárias.

Ao contrário, nas regiōes desenvolvidas, predominariam valores universais, seculares e partidos modernos. O Executivo federal seria um representante destas forças, e a negociação com os parlamentares dessas regiōes seria feita predominantemente em torno de políticas e de programas partidários. Como as regiōes ditas "atrasadas" são também as sobre-representadas, o impacto disso seria sensível, fazendo com que o "presidencialismo de coalizão" existente no Brasil envolvesse não apenas as negociações realizadas com um conjunto de partidos fragmentados, mas também com atores regionais fortes. $\mathrm{Na}$ visão dessa corrente, esse seria um ponto de veto a mais para emperrar o já complicado sistema decisório.
No entanto, essa visão não é unânime. Há autores que realçam os aspectos positivos da desproporcionalidade de representação, deixando a ideia de que o enfoque exacerbado sobre ela é tanto simplório quanto preconceituoso. Para Santos (1987), a sobre-representação dos estados menores tem o mérito de evitar a tirania da maioria. Soares e Lourenço (2004) argumentam que uma representação proporcional levaria a uma maior coincidência entre o poder econômico e o poder político, aumentando o grau de desequilíbrio federativo. Segundo os autores, isso seria particularmente grave para o caso de São Paulo, que passaria a contar com mais de $20 \%$ da representação na Câmara dos Deputados, sem deixar de ser responsável por 33,4\% do PIB nacional - quando os estados do Norte, do Nordeste e do Centro-Oeste conjuntamente respondem por apenas $25 \%$ dele.

Diante dos amplos poderes do Senado, da sua capacidade de influência sobre o sistema político, do seu caráter federativo e das suas peculiaridades organizacionais, entendemos que ele merece análises específicas. Como uma câmara territorial, representante dos estados da federação, ele deve ser considerado nesta agenda de pesquisa, que busca explicar o comportamento dos legisladores nacionais. A despeito dos argumentos de Cheibub, Figueiredo e Limongi (2009) para justificar o foco sobre a Câmara dos Deputados, ${ }^{6}$ julgamos que vale a pena o esforço de incluir o Senado nesse debate. Na seção que se segue, iniciamos a análise dos dados com a apresentação da metodologia que será utilizada.

\section{Variáveis e aspectos metodológicos}

Analisamos o comportamento dos senadores a partir das votações nominais realizadas em plenário. Cabe dizer que uma quantidade pequena das propostas apresentadas são votadas nominalmente, isto é, exigindo que o parlamentar declare o seu voto abertamente. O procedimento é realizado em situações específicas: para as propostas de emendas constitucionais; para os projetos de lei complementar; por deliberação do plenário, quando houver pedido de verificação de quorum. Este último é solicitado em função de cálculos políticos, 
geralmente para reverter as decisões tomadas, ou para impor custos aos seus adversários, que deverão registrar seus votos.

O período analisado abrange vinte anos (1989 a 2008), envolvendo o mandato de cinco presidentes: José Sarney (último ano), Fernando Collor (31 meses), Itamar Franco (27 meses), Fernando Henrique (8 anos) e Lula da Silva (6 anos). Neste intervalo de tempo, identificamos 1.319 votaçóes nominais válidas - aquelas que obtiveram o quórum mínimo de maioria absoluta, isto é, a presença de pelo menos 41 senadores em plenário. A exemplo de outros estudos na área, retiramos da amostra as que apresentaram baixo grau de conflito, isto é, que tiveram menos de $10 \%$ de divergência. Restaram apenas 497 votações ou 37,7\% do total. Esse número é substancialmente menor do que os $71 \%$ encontrados por Cheibub, Figueiredo e Limongi (2009) na Câmara dos Deputados. Tais resultados mostram que o Senado aprova a maioria das matérias que vem da Câmara, sem muita controvérsia, limitando-se a revisar um número relativamente pequeno delas. Uma interpretação possível é de que ele não gasta tempo com matérias que foram amplamente discutidas na outra Casa, reservando uma atuação mais decisiva naquelas que efetivamente envolvam um grau de conflito maior. Essa é uma discussão interessante, que merece ser realizada, mas foge dos propósitos desse artigo.

A nossa variável dependente diz respeito aos votos favoráveis ao governo no período selecionado. Consideramos, como tal, aqueles que coincidiram com o voto dado pelo líder do governo no plenário. Ao contrário do que fazem os estudos sobre a Câmara dos Deputados, não seria conveniente considerar as indicações feitas verbalmente pelas lideranças. Pelo fato de o Senado ser uma casa pequena, onde a comunicação flui de maneira fácil e informal, tais indicações são menos frequentes e, muitas vezes, desnecessárias. Caso decidíssemos tomá-las como referência, teríamos que abrir mão de mais da metade da nossa amostra.

A principal variável independente é a que avalia se os senadores são influenciados pela vontade do governador. Não é possível saber com certeza a posição dos governadores em cada uma das votações, até por que eles raramente se manifestam publicamente sobre elas. Por esse motivo, a exemplo do que fazem Cheibub, Figueiredo e Limongi (2009), estamos considerando que ela seria expressa pelo voto do líder do seu respectivo partido em plenário. Caso coincida com o voto do líder do governo federal, ele será considerado um voto favorável ao governo; caso contrário, um voto desfavorável. Portanto, um coeficiente positivo e significativo para essa variável reforça a hipótese de que os governadores influenciam as respectivas bancadas estaduais no Senado.

Uma análise mais completa deve controlar a influência de outros fatores relevantes. O primeiro deles identifica se o parlamentar é de um partido que faz parte da coalizão governamental. Como mostra ampla literatura na área, a filiação partidária tem-se mostrado a principal explicação para a decisão de votos dos deputados federais, o que torna a sua presença fundamental em qualquer modelo explicativo desse tipo.

Outras variáveis importantes para serem analisadas em um estudo sobre atuação parlamentar dizem respeito às características de suas respectivas regiôes de origem, especialmente quando a Casa legislativa em questão é uma câmara territorial. Segundo Selcher (1998), o apelo regional é muito mais frequente nos políticos de regiōes mais pobres do que nos de regiōes ricas. Nestas últimas, os interesses são mais pluralistas, segmentados por partido e por setor econômico, ao contrário do que acontece nas outras regiōes, onde a estrutura hierárquica é menos complexa e os cidadãos são menos mobilizados politicamente.

Para testar (e controlar) a influência dos aspectos regionais, utilizaremos duas estratégias diferentes. Na primeira, faremos uma divisão bastante simples, que segmenta o Brasil em regiōes mais desenvolvidas (Sul e Sudeste) e menos desenvolvidas (Norte, Nordeste, Centro-Oeste). No entanto, apesar de as regióes se diferenciarem entre si, nem sempre elas apresentam homogeneidade interna: o estado de São Paulo, por exemplo, é muito diferente do Espírito Santo, apesar de ambos estarem no Sudeste. Sendo assim, o procedimento acima serve, tão somente, para testar os argumentos apresentados por parte da literatura que enfatiza a explicação a partir da localização regional exclusivamente. 
Em uma segunda estratégia, recorreremos a medidas mais precisas, onde os estados serão considerados individualmente. Faremos isso utilizando três variáveis que, a nosso ver, expressam razoavelmente bem a desigualdade entre eles. A primeira será o índice de desenvolvimento humano (IDH) do estado pelo qual o senador foi eleito. Trata-se de indicador amplamente utilizado nas ciências sociais, formado a partir das variáveis renda, longevidade e educação, as quais retratam tanto aspectos econômicos quanto sociais. Tendo em vista que o nosso estudo abrange vinte anos e que o índice não costuma variar bruscamente, utilizaremos os dados do ano 2000, que reflete bem a média de todo o período.

A segunda variável, que também diferencia muito os estados entre si, diz respeito à desproporcionalidade de representação, uma característica marcante do Senado brasileiro. Gibson, Calvo e Falleti (2004) analisaram quatro países federativos, chegando à conclusão que os estados sobre-representados recebiam mais gastos discricionários no Brasil e na Argentina, o que não acontecia no México e nos Estados Unidos, onde não existia tal desproporcionalidade na câmara baixa. Tais resultados foram mantidos mesmo depois de os autores controlarem os efeitos de pobreza e de renda. Neste artigo, ela será calculada de acordo com o tradicional "índice D" (Loosemore e Hanby, 1971), o qual utiliza a seguinte fórmula: $D=1 / 2 S 1 / 2 c-c^{1} 1 / 2$, onde $c$ é o percentual de cadeiras de cada estado (3,7\% para cada um deles, equivalente a três cadeiras) e $c h$ é o percentual da população dessa unidade da federação no ano 2000.

Recentemente, Carvalho (2009) trouxe uma perspectiva diferente para a percepção da desproporcionalidade de representação: aquela que aparece por conta do grau de urbanização. Segundo o autor, as áreas urbanas - notadamente capitais, regiōes metropolitanas e as grandes cidades - teriam cerca de cem cadeiras a mais na Câmara dos Deputados, caso não houvesse desproporcionalidade. A situação ganha relevância pelo fato de se tratar, na opiniāo do autor, de um voto de qualidade superior, que se move por orientação ideológica. Nesse aspecto, ele contrasta com o voto das áreas rurais, sujeitas a uma estrutura social fortemente verticalizada e hierarquizada, imbuída de clientelismo, particularismo e paroquialismo na arena legislativa. Sendo assim, o grau de urbanização do estado será a terceira variável que reflete as características estaduais a ser incluída no nosso modelo.

Além das características regionais, controlaremos o efeito que atributos pessoais dos parlamentares e da própria matéria em votação possam ter sobre o resultado. No primeiro caso, incluiremos no modelo informações sobre exercício do cargo de lideranças. Como os líderes contam com acesso privilegiado ao governo federal, é de se esperar que eles tenham uma postura mais favorável à agenda governamental. Levaremos também em consideração o fato de os senadores serem titulares ou suplentes. Esses últimos parecem ter uma importância especial, já que não recebem um único voto e representam aproximadamente $20 \%$ dos senadores que passaram pela Casa (Neiva e Izumi, 2012b). No caso das votações, entraremos com uma variável que indica se elas se referem a uma matéria substantiva, isto é, que diz respeito ao mérito e não a alguma questão procedimental. Na seção que se segue, iniciamos a análise dos dados.

\section{Análise dos dados}

A análise dos dados será feita em duas etapas, tomando como referência as 497 votações nominais selecionadas na seção anterior. Na primeira etapa, apresentamos uma estatística descritiva dos votos dos senadores que fazem parte da base de apoio ao governo, em duas situações que nos interessam no presente contexto: quando o partido do governador está na coalizão governamental e quando está na oposição. O propósito é verificar se a oposição do governador faz ou não diferença para o voto dos legisladores situacionistas. Em caso afirmativo, espera-se que o governo receba maior apoio dos senadores cujo estado não é dirigido por um governador de oposição. Os resultados são apresentados na Tabela 1 .

Em concordância com os achados de Cheibub, Figueiredo e Limongi (2009) para os deputados, os resultados mostram que o fato de o governador ser de um partido que não faz parte da coalizão do governo federal não provoca um efeito negativo sobre 
Tabela 1

Apoio ao Governo Federal Entre os Senadores da Base Governamental: Governador Alinhado à Coalizão do Governo versus Governador de Oposição

\begin{tabular}{lllll}
\hline \multirow{2}{*}{ Governo } & \multicolumn{2}{l}{ Governo faz parte da coalizão } & \multicolumn{2}{l}{ Governo de oposição } \\
\cline { 2 - 5 } & $\%$ & $\mathrm{~N}$ & $\%$ & $\mathrm{~N}$ \\
\hline Sarney & 57,57 & 304 & 60,29 & 68 \\
\hline Collor & 74,48 & 239 & 81,86 & 408 \\
\hline Itamar & 72,81 & 1324 & 69,41 & 559 \\
\hline FHC 1 & 80,81 & 6827 & 82,60 & 2362 \\
\hline FHC 2 & 78,49 & 2669 & 71,21 & 1254 \\
\hline Lula 1 & 77,72 & 1010 & 79,25 & 1094 \\
\hline Lula 2 & 83,29 & 766 & 86,58 & 447 \\
\hline Todos & 78,83 & 13139 & 78,50 & 6192 \\
\hline
\end{tabular}

Fonte: Banco de Dados Legislativos do Cebrap.

os votos dados pelos senadores no plenário. Com exceção do segundo mandato de Fernando Henrique e do mandato "tampão" de Itamar, o apoio ao governo foi maior nessas condições. No período todo, a média geral de apoio dos dois grupos ficou muito parecida, praticamente igual: $78,83 \%$ quando os governadores seriam supostamente favoráveis ao governo federal e $78,5 \%$ no caso contrário. ${ }^{7}$

A despeito da influência dos governadores ser parecida na Câmara e no Senado, o apoio ao governo nacional no segundo é razoavelmente menor. Um fator que pode estar contribuindo para isso é o fato de que a retirada das votaçóes unânimes ou quase unânimes - as que apresentam menos de $10 \%$ de divergência - surte um efeito muito maior no Senado; consequentemente, as que restam apresentariam um grau de conflito supostamente maior. Outra explicação viria do fato de que os senadores estão em uma posição mais avançada da carreira política em relação aos deputados, o que lhes daria maior autonomia às pressóes e aos incentivos oriundos do governo federal.

Para uma análise mais completa, apresentamos a seguir três modelos de regressão logística, que permitem controlar outros fatores supostamente importantes para explicar o voto dado pelo parlamentar. ${ }^{8}$ No modelo 1 , além das variáveis de in- teresse, incluímos informações sobre a região de origem dos senadores. Especificamente, se eles são provenientes de uma das três regióes mais pobres, que estão sendo comparadas com as duas regióes que foram omitidas (Sul e Sudeste). No modelo 2, retiramos as variáveis referentes às regióes e incluímos informações específicas sobre os estados: IDH e desproporcionalidade de representação.

No intuito de evitar problemas de multicolinearidade, utilizamos variáveis mutuamente excludentes nos modelos 2 e 3. A variável "população urbana” substituiu a variável referente ao IDH, e a variável que controla o fato de ser uma matéria importante (substantiva) foi substituída pela variável que controla o fato de se tratar de uma matéria federativa. Alternativamente, incluímos termos interativos que testam o fato de o senador fazer parte da coalizão e o governador ser de oposição. Como a melhoria no ajuste não foi significativa, deixamos de incluí-los nos modelos que se seguem.

A Tabela 2 mostra alguns resultados interessantes. Em primeiro lugar, confirma a importância dos partidos, mais especificamente da coalizão governamental, na decisão de voto dos senadores. A exemplo do que acontece na Câmara dos Deputados, o governo parece ter controle sobre uma base parlamentar sólida no Senado. Fazer parte da base de 
Tabela 2

Determinantes do Voto Favorável ao Governo Federal, em todas as Matérias

\begin{tabular}{|c|c|c|c|}
\hline & 1 & 2 & 3 \\
\hline & Odds Ratio & Odds Ratio & Odds Ratio \\
\hline \multirow{2}{*}{ Coalizão de governo } & $4,65^{* * *}$ & $4,65^{* * *}$ & $4,61^{* * *}$ \\
\hline & $(54,96)$ & $(54,90)$ & $(54,62)$ \\
\hline \multirow{2}{*}{ Governador de Oposição } & 1,01 & 1,02 & 1,03 \\
\hline & $(0,41)$ & $(0,78)$ & $(1,11)$ \\
\hline \multirow[t]{2}{*}{ Norte } & $1,27^{* * *}$ & - & - \\
\hline & $(6,49)$ & & \\
\hline \multirow[t]{2}{*}{ Centro-Oeste } & $1,30^{* * *}$ & - & - \\
\hline & $(6,06)$ & & \\
\hline \multirow[t]{2}{*}{ Nordeste } & $1,07^{*}$ & - & - \\
\hline & $(1,98)$ & & \\
\hline \multirow[t]{2}{*}{ Matéria Substantiva } & $0,93^{* *}$ & $0,93^{* *}$ & - \\
\hline & $(-2,19)$ & $(-2,20)$ & \\
\hline \multirow[t]{2}{*}{ Matéria Federativa } & - & - & 1,01 \\
\hline & & & $(0,44)$ \\
\hline \multirow[t]{2}{*}{ Líder } & $1,16^{* * *}$ & $1,14^{* * *}$ & $1,14^{* * *}$ \\
\hline & $(3,81)$ & $(3,25)$ & $(3,27)$ \\
\hline \multirow[t]{2}{*}{ Titular } & $0,72^{* * *}$ & $0,73^{* * *}$ & $0,73^{* * *}$ \\
\hline & $(-7,87)$ & $(-7,55)$ & $(-7,57)$ \\
\hline \multirow[t]{2}{*}{ IDH } & - & 0,68 & - \\
\hline & & $(-1,59)$ & \\
\hline \multirow[t]{2}{*}{ Desproporcionalidade } & - & $1,00^{* * *}$ & $1,02^{* * *}$ \\
\hline & & $(3,81)$ & $(3,67)$ \\
\hline \multirow[t]{2}{*}{ População Urbana } & - & - & $0,99^{* * *}$ \\
\hline & & & $(-3,38)$ \\
\hline Observações & 29.223 & 29.223 & 29.223 \\
\hline R2 Ajustado & 0,094 & 0,094 & 0,093 \\
\hline Log likelihood & $-16415,17$ & $-16437,55$ & $-16435,48$ \\
\hline
\end{tabular}

Estatística "t" entre parênteses. ${ }^{* * *} \mathrm{p}<0.01,{ }^{* *} \mathrm{p}<0.05,{ }^{*} \mathrm{p}<0.10$

apoio ao governo aumenta em $365 \%{ }^{9}$ a chance de que o senador venha a votar favoravelmente a ele. Já o governador do estado não parece ter influência sobre a decisão de votos dos senadores. $\mathrm{O}$ fato de ele ser de um partido de oposição não faz com que os senadores votem desfavoravelmente ao governo. Pelo contrário, o efeito da variável é positivo, ainda que não tenha apresentado significância estatística. Esses resultados são repetidos nos modelos 2 e 3 e sugerem que existe um mecanismo agregador das decisões tomadas no plenário do Senado, o qual parece girar em torno do poder Executivo, reforçando a corrente da literatura que avalia positivamente o funcionamento do sistema político brasileiro. 
O primeiro modelo mostra também que os senadores das regióes menos desenvolvidas tendem a apoiar mais o governo do que os das regióes mais desenvolvidas. Tal resultado sugere que a sobre-representação dessas regiōes (deixada de fora desse modelo) pode ter algum efeito, ainda mais se observarmos que o Norte e o Centro-Oeste, onde a desproporcionalidade é efetivamente alta, apresentaram significância estatística ao nível de $1 \%$. Tal suspeita é confirmada nos modelos 2 e 3, onde a variável referente à desproporcionalidade (ou à sobre-representação, se quiserem) apresentou-se como muito importante para explicar o voto de um senador. Esses resultados trazem de volta a discussão sobre a relevância das variáveis externas ao Legislativo para ajudar a explicar o comportamento dos legisladores. Não foi possível verificar, no âmbito deste trabalho, o impacto da proporção de votos recebidos pelos senadores, mas essa é uma análise que merece ser realizada. Afinal, há grande diferença também entre os próprios senadores de um mesmo estado, não só no que diz respeito ao número de votos, mas também no seu grau de concentração/dispersão.

A Tabela 2 mostra ainda que, nas decisões finais (matérias substantivas, ou não procedimentais), o governo federal tende a ter um pouco mais de dificuldade para fazer prevalecer a sua vontade. Já o controle realizado pela variável que identifica se a matéria é ou não federativa não apresentou significância estatística.

No que diz respeito às características individuais dos parlamentares, dois resultados importantes apareceram. O primeiro deles mostra que os líderes tendem a apoiar mais o governo, o que não é surpreendente, já que os partidos importam e que a maioria deles faz parte da coalizão governamental. Outro resultado interessante foi o apresentado pela variável que diz se o senador é titular ou suplente. Os dados mostram que os suplentes ajudam o governo a completar a sua maioria na Casa. Como eles respondem por aproximadamente $16 \%$ dos votos dados no período, sua atuação pode ser decisiva em muitas matérias que passam com quorum apertado. Não se pode dizer, com segurança, que os suplentes são facilmente cooptáveis; mas o fato de eles não terem qualquer compromisso com o eleitor permi- te que tenham ampla liberdade para decidir sem a necessidade de prestar contas, a não ser ao senador titular que o colocou no cargo. Notícias da imprensa dão conta de que uma boa quantidade de suplentes é escolhida com base em dois critérios: por parentesco e por financiarem as campanhas dos titulares. Não temos informações detalhadas sobre essa prática e acreditamos que ela não seja universal. Não obstante, trata-se de um fenômeno pouco condizente com o grau de consolidação da democracia no país. Cabe à ciência política investigar mais profundamente essa categoria de parlamentar, especialmente no Senado, onde eles não passam pelo crivo popular.

Por fim, a tabela mostra que os estados mais desenvolvidos e mais urbanos tendem a apoiar menos o poder Executivo. No caso do IDH, ele não chegou a apresentar significância estatística. Já o grau de urbanização do estado mostrou-se altamente significativo na explicação da falta de apoio à agenda governamental. Esses não são resultados conclusivos, já que muitos parlamentares tem sua base eleitoral concentrada em um ou em poucos municípios, e não sobre o estado inteiro. No entanto, eles alertam sobre a necessidade de se investir um pouco mais de energia na observação de características outras que não as variáveis institucionais, como tem sido a prática predominante nos estudos legislativos no país. Pelo que estamos vendo nessa pesquisa, o peso das características geográficas/ regionais no funcionamento da casa supostamente territorial não é desprezível, ainda que a situação política do governador não pareça ser relevante.

Os resultados mostram o impacto de diversas variáveis sobre a decisão de votos dos senadores em todos os tipos de assuntos. No entanto, poder-se-ia argumentar que não seria adequado avaliar a influência de atores que representam interesses regionais/ territoriais a partir de matérias que não afetam diretamente seus interesses (Desposato, 2004). Na verdade, a seleção da amostra de votações depende do propósito do pesquisador. Nos modelos apresentados, estamos testando a hipótese de que os governadores influenciam a elaboração das políticas nacionais (por meio da ingerência sobre os votos dos representantes dos seus estados), controlando pelo fato de elas, eventualmente, terem um impacto sobre a política regional/estadual. Dito de outra forma, 
Tabela 3

Determinantes do Voto Favorável ao Governo Federal, nas Matérias de Interesse dos Estados

\begin{tabular}{|c|c|c|}
\hline & 1 & 2 \\
\hline & Odds Ratio & Odds Ratio \\
\hline Coalizão de Governo & $\begin{array}{l}4,38^{* * *} \\
(24,82) \\
\end{array}$ & $\begin{array}{l}4,48^{* * *} \\
(25,31) \\
\end{array}$ \\
\hline Governador de Oposição & $\begin{array}{l}0,98 \\
(-0,27) \\
\end{array}$ & $\begin{array}{l}0,97 \\
(-0,49) \\
\end{array}$ \\
\hline Norte & $\begin{array}{l}1,03 \\
(0,34) \\
\end{array}$ & - \\
\hline Centro-Oeste & $\begin{array}{l}1,23^{* *} \\
(2,26)\end{array}$ & - \\
\hline Nordeste & $\begin{array}{l}0,80^{* * *} \\
(-2,22)\end{array}$ & - \\
\hline Líder & $\begin{array}{l}1,06 \\
(0,68)\end{array}$ & $\begin{array}{l}1,00 \\
(0,04) \\
\end{array}$ \\
\hline Titular & $\begin{array}{l}0,68^{* * *} \\
(-4,27) \\
\end{array}$ & $\begin{array}{l}0,70^{* * *} \\
(-3,85)\end{array}$ \\
\hline IDH & - & $\begin{array}{l}0,70 \\
(-0,71) \\
\end{array}$ \\
\hline Desproporcionalidade & - & $\begin{array}{l}1,02^{*} \\
(1,69) \\
\end{array}$ \\
\hline População Urbana & $\begin{array}{l}0,98^{* * *} \\
(-3,92)\end{array}$ & - \\
\hline Observações & 6543 & 6543 \\
\hline R2 Ajustado & 0,094 & 0,092 \\
\hline Log likekihood & $-3665,78$ & $-3677,39$ \\
\hline
\end{tabular}

Estatística "t" entre parênteses. ${ }^{* * *} \mathrm{p}<0.01,{ }^{* *} \mathrm{p}<0.05,{ }^{*} \mathrm{p}<0.10$

estamos avaliando até que ponto os governadores interferem ou não na posição dos senadores quando votam no plenário do Senado, tomando como referência os propósitos do Executivo nacional, independentemente de as matérias votadas terem ou não um interesse para seus respectivos estados.

Se o propósito for avaliar se os governadores influenciam na elaboração de políticas de interesse regional, especificamente, o controle realizado pela variável "matéria federativa" não é suficiente. Nesse caso, torna-se necessário selecionar uma amostra diferenciada, que envolva apenas as propostas legislativas que afetem os estados. É o que fazemos na tabela que se segue. ${ }^{10}$
Os resultados confirmam as conclusões principais dos modelos anteriores. Fazer parte da coalizão governamental é um elemento fundamental na explicação do apoio dado ao governo. Em outras palavras, a filiação partidária é importante no comportamento dos parlamentares: pertencer a um partido que integra a base de sustentação do governo no Legislativo continua sendo uma referência importante para a tomada de decisão dos senadores, também nas matérias de interesse específico dos estados.

$\mathrm{O}$ fato de o senador ser proveniente de um estado onde o governador é filiado a um partido de oposição ao governo federal não se apresentou como um elemento importante para explicar o 
apoio (ou falta dele) à agenda nacional. Os senadores não parecem ser influenciados pelos governadores de seus estados, mesmo nas matérias de natureza federativa.

O comportamento das variáveis relativas ao aspecto regional mudou de feição, em relação ao que aconteceu na Tabela 2 . As regióes menos desenvolvidas deixaram de ter um comportamento homogêneo, quando comparadas com as regiōes mais desenvolvidas (omitidas nos dois modelos). As regióes Norte e Centro-Oeste apresentaram um impacto positivo, mas ele só é significativo no caso desta última. A região Nordeste apresentou um impacto negativo.

As conclusões referentes à variável que especifica se o senador é o titular do cargo foram mantidas e reforçadas, mesmo quando limitamos a amostra às matérias federativas. Os titulares tendem a apoiar menos o poder Executivo, quando comparados com os suplentes. Vale registrar ainda o impacto da variável referente à população urbana, que apresentou sinal negativo e significância estatística. A desproporcionalidade de representação também manteve o sinal apresentado nos modelos anteriores, embora a significância estatística tenha-se reduzido: senadores representantes de estados sobre-representados tendem a apoiar mais a agenda do Executivo federal do que os de estados sub-representados.

\section{Considerações finais}

Nossa análise foi realizada em duas etapas, uma envolvendo as matérias legislativas em geral e outra restrita àquelas de natureza federativa. Nossos achados reforçam a corrente da literatura que avalia positivamente as instituições políticas do país, mostrando que a variável referente aos partidos, mais especificamente a coalizão de partidos governantes, apresentou-se como a mais importante para explicar o voto congruente com o que desejava o governo federal.

Já a influência dos governadores não se mostrou expressiva. Não se confirmou a ideia de "uma assembleia composta por vinte e sete estados" ou de que os "barões da federação" tenham se tornado um "quarto poder da República”. Isso aconteceu tanto nas votaçóes gerais como nas de caráter federativo. Ainda que os governadores, em seu conjunto, tivessem força política para pressionar o poder Executivo, faltou-lhes capacidade de coordenação, uma força centralizadora e agregadora que organizasse sua ação coletiva. A possibilidade de que isso venha a acontecer parece muito remota, pois não existe homogeneidade entre eles. Pelo contrário, as desigualdades regionais no Brasil são imensas e perpassam os aspectos econômicos, produtivos, sociais ou mesmo históricos. Os interesses de São Paulo são muito diferentes dos que são defendidos pelo Piauí, pelo Acre ou pelo Amazonas; são diferentes até mesmo dos seus vizinhos mais parecidos como Minas Gerais e Paraná.

Além das variáveis tradicionalmente utilizadas nas análises de votaçôes nominais, incluímos também informaçôes relativas aos respectivos estados e aos próprios senadores individualmente. Os resultados sugerem também a existência de uma negociação diferenciada de senadores de regiōes sobre-representadas, menos urbanas e, geralmente, mais pobres, com o poder Executivo nacional. Destaca-se ainda a relevância dos senadores suplentes que, apesar de não serem eleitos e de representarem apenas 16\% dos votos da Casa, parecem ser atores decisivos em votações mais conflituosas.

O Senado ainda é uma instituição pouco estudada. Muitas crenças que temos a seu respeito precisam ser mais bem investigadas. Uma delas é a de que ele representa os interesses dos estados e tende a atender suas demandas, ficando a representação popular com a câmara baixa. A ideia vem sendo propagada desde "os federalistas" nos Estados Unidos, o primeiro país a adotar um arranjo federativo no mundo. No Brasil, ela se difundiu, a ponto de termos colocado tal preceito no texto constitucional. Acreditamos que a investigação do Senado com essa ideia fixa pode ser pouco produtiva. Afinal, que representação é essa, qual o seu propósito, o que defende e a quem está definitivamente defendendo? Essas são perguntas importantes para termos uma compreensão mais completa da nossa poderosa câmara alta. As justificativas apresentadas pelos "pais fundadores" da confederação norte-americana podem não servir para o sul do 
continente. Talvez não sirva nem para eles, pois há quem questione que o real propósito da criação do Senado (desproporcional) dos Estados Unidos não teria sido uma forma de garantir que os estados menores não fossem subjugados pelos estados maiores, como diz a história oficial. Na verdade, ela pode ter sido uma forma de preservar os interesses das elites escravistas do sul do país; se deixassem que as decisões importantes fossem tomadas exclusivamente nas mãos da câmara baixa proporcional, onde predominavam os estados progressistas do norte, ela facilmente acabaria com a escravidão. De fato, a abolição só veio a acontecer efetivamente quase um século depois, com a guerra de secessão em 1865. No Brasil, precisamos também rediscutir a nossa matriz federativa; e o funcionamento do Senado e os interesses das elites regionais ali representadas parecem fundamentais nesse debate.

A representação e a defesa dos interesses dos estados (ou de suas elites) não é tampouco sua única vocação, e talvez não seja a principal. Há evidências de que a formação de uma federação não foi feita, aqui ou alhures, apenas para atender as demandas e defender os interesses das subunidades constituintes (Tocqueville, 2003; Riker, 1964). Ela é vista também como uma forma de permitir que os interesses gerais da União sejam viabilizados. Mais apropriada parece ser a ideia de que o Senado tem desempenhado, também no Brasil, um papel importante na negociação entre os dois níveis de governo. Em vez de defender os interesses puramente regionais, ele tem exercido um papel centralizador, imprimindo um caráter mais nacional às decisões tomadas e às políticas implementadas. A impressão que fica no final deste estudo - e os dados nos ajudam nisso - é de que o Senado brasileiro é uma Casa mais preocupada com os assuntos nacionais do que os regionais ou estaduais. Ainda que sejam sensíveis aos interesses de seus estados, os senadores não parecem dar um apoio menor à agenda nacional. No período analisado, ele teve um papel decisivo no processo de reformas estruturais, ajuste fiscal e estabilização econômica. Apesar da pressão de suas bases eleitorais, como antigos (ou futuros) governadores e presidentes, os senadores parecem ter melhor compreensão e maior responsabilidade diante dos problemas típicos do poder Executivo.

\section{Notas}

1 As contagens de países bicamerais e federativos foram feitas com base nos sítios da Interparliamentary Union (www.ipu.org) e do Forum of Federations (www.forumfed.org), respectivamente.

2 Essas informações ganham relevância ainda maior se admitirmos que o aumento de tal desproporcionalidade não foi casual, mas pode estar relacionado com a forma como se deu a transição democrática no país. A desproporcionalidade favorece o PMDB, que tem sido a maior bancada do Senado desde a retomada da democracia em meados dos anos de 1980. Não só pelo tamanho, mas também pela posição central que ocupa no espectro político e pela inserção que tem nas regiões sobre-representadas, o PMDB foi o principal partido no processo de transição negociada que aconteceu no Brasil. No entanto, essa é apenas uma especulação que merece ser mais bem investigada.

3 No início dos anos de 1990, cada estado tinha pelo menos um banco estadual autônomo. Nem a câmara baixa, nem o Banco Central tinha controle sobre os empréstimos internacionais das subunidades da federação. No final das contas, os estados tinham efetivo poder de emissão de moeda, por meio da emissão de títulos (Stepan, 2000).

4 Os principais poderes legislativos do presidente são: prerrogativa de propor legislação em áreas específicas, como o orçamento; poder de veto; possibilidade de solicitar urgência na tramitação de matérias de sua autoria; possibilidade de editar medidas provisórias.

5 Entre as medidas citadas por Abrucio e Loureiro (2004), estão as seguintes: em 1997, criou a chamada "CPI dos Precatórios", destinada a investigar irregularidades na emissão de títulos públicos; em julho de 1998 , foi baixada a resolução $78 / 98$, que vedava a emissão de novos títulos para governos já endividados, delegando ao Banco Central a prerrogativa de autorizar o endividamento de governos com resultado primário negativo; em dezembro de 2001, transferiu do Banco Central para a Secretaria do Tesouro nacional o poder de decidir sobre os pedidos de tais endividamentos.

6 Os seguintes argumentos são apresentados por tais autores para justificar o foco sobre a câmara baixa, e não sobre o Senado: 1) as propostas do Executivo entram no Congresso pela Câmara dos Deputados; 2) o sistema eleitoral da Câmara - representação proporcional de lista aberta - tem o efeito de induzir a fragmentação do partido, induzindo o individualismo entre os legisladores; 3) o pequeno número de senadores por 
distrito (estado) comprometeria a validade das análises estatísticas.

7 No governo Sarney, o nível de apoio recebido pelo Executivo foi razoavelmente mais baixo do que nos outros governos. No entanto, o número pequeno de casos não nos permite ir muito além nessa avaliação.

8 Vale lembrar que, diferentemente da Tabela 1, aqui estamos trabalhando com todos os senadores - os que apoiam o governo e os de oposição a ele -, o que explica a diferença no número de casos.

9 Para o leitor pouco familiarizado com estatística, explicamos a origem desse número: transformamos o coeficiente da variável "coalizão de governo" no modelo $1(4,65)$, expresso em razões de chance, para um formato percentual, da seguinte forma: $(4,65-1)$ * $100=365$. Outra possibilidade, considerada mais difícil por alguns, seria fazer a interpretação direta, do tipo: "o fato de fazer parte da coalizão do governo aumenta em 4,65 vezes a chance de o senador votar a favor do governo, em relação à chance de não votar a favor".

10 Agradecemos a Marta Arretche por nos disponibilizar sua classificação de matérias federativas. A autora identificou 28 propostas de emendas constitucionais de caráter federativo analisadas no Senado no período de 1989 a 2008. Tais matérias geraram 99 votações nominais, que estão sendo utilizadas nesta análise.

\section{BIBLIOGRAFIA}

ABRANCHES, Sérgio. (1988), "O presidencialismo de coalizão: o dilema institucional brasileiro". Dados, 31 (1): 5-33.

ABRUCIO, Fernando. (1998), Os baróes da federação: os governadores e a redemocratização brasileira. São Paulo, Hucitec.

AFFONSO, Rui. (1994), "A crise da federação no Brasil". Ensaios FEE, 15 (2): 321-337.

AMES, Barry. (2003), Os entraves da democracia no Brasil. Rio de Janeiro, FGV.

ANCKAR, D. (1999). "Homogeneity and smallness: Dahl and Tufte revisited". Scandinavian Political Studies, 22 (1): 29-44.

ARAÚJO, Paulo (2008). "A câmara alta no Legislativo brasileiro: o desempenho legislativo do Senado entre 1989 e 2000", in Leany Lemos (org.), O Senado federal brasileiro no pós-Consti- tuinte. Brasília, Editora do Senado Federal, pp. 203-236.

ARRETCHE, Marta. (2011), "Federalism, bicameralism and institutional change: general trens and one case study". Brazilian Political Science Review, 4 (2): 10-31.

(2002), "Federalismo e relaçôes intergovernamentais no Brasil: a reforma de programas sociais". Dados, 45(3): 431-458.

AVELAR, Lúcia \& WALTER, Maria Inês. (2008), "Lentas mudanças: o voto e a política tradicional”. Opinião Pública, 14 (1): 96-122.

BACKES, Ana. (1999), "Bicameralismo no Brasil: o que pode uma minoria”. Caderno ASLEGIS, 3 (7): 9-23.

BOHN, Simone. (2007), "Women and candidate quality in the elections for the Senate: Brazil and the United States in comparative perspective”. Brazilian Political Science Review, 1 (2): 74-107.

BRANCO, Marcelo. (2008), "A atuação do Senado Federal no processo de ajuste fiscal dos anos 90", in Leany Lemos (org.), O Senado federal brasileiro no pós-Constituinte. Brasília, Editora do Senado Federal, pp. 273-328.

(2009), "Uma discussão sobre os efeitos institucionais do Senado federal brasileiro". Revista Liberdade e Cidadania, 2 (5): 1-10.

CARVALHO, Nelson. (2009, "Geografia política das eleiçôes congressuais: a dinâmica de representação das áreas urbanas e metropolitanas no Brasil”. Cadernos Metrópole, 11 (22): 367-384. CHEIBUB, José Antônio; FIGUEIREDO, Argelina \& LIMONGI, Fernando. (2002), "Presidential agenda power and decision-making in presidential regimes: governors and political parties in the Brazilian Congress". Trabalho apresentado no Encontro Anual da American Political Science Association, Boston, 29 de agosto a 1 de setembro.

- (2009), "Partidos políticos e governadores como determinantes do comportamento legislativo na Câmara dos Deputados, 19882006". Dados, 52: 263-299.

DESPOSATO, Scott. (2004), "The impact of federalism on national party cohesion in Brazil". Legislative Studies Quarterly, pp. 259-285. 
FIGUEIREDO, Argelina \& LIMONGI, Fernando. (1996), "As reformas (des)necessárias". São Paulo em Perspectiva, 10 (4): 37-43.

(1999), Executivo e Legislativo na nova ordem constititucional. Rio de Janeiro: FGV. . (2000), "Presidential power, legislative organization, and party behavior in Brazil". Comparative Politics, 32 (2): 151-170.

GIBSON, E.; CALVO, E. \& FALLETI, T. (2004), "Reallocative federalism: Legislative overrepresentation and public spending in the western hemisphere", in E. Gibson (ed.), Federalism and democracy in Latin America. Baltimore, The John Hopkins University Press, pp. 173196.

HELLER, William. (1997), "Bicameralism and budget deficit: the effect of parliamentary structure on government spending". Legislative Studies Quarterly, 22 (4): 485-516.

HIROI, Taeko. (2008), "The dynamics of lawmaking in a bicameral legislature: the case of Brazil". Comparative Political Studies, 41 (12): 1583-1606.

INÁCIO, Magna \& ARAÚjO, Paulo. (2011), "Dinámica intercameral y coordenación partidista em Brasil”, in Manuel Alcántara e Mercedes García Montero (orgs.), Algo más que presidentes: el papel del poder Legislativo em América Latina. Zaragoza, Fundación Manuel Giménez Abad de Estudios Parlamentarios y del Estado Autonómico, pp. 363-391.

IZUMI, Maurício. (2010), "Padrão de carreira dos senadores brasileiros (1989-2008)". Trabalho apresentado no VII Encontro da Associação Brasileira de Ciência Política, Recife (PE).

LEMOS, Leany \& LLANOS, Mariana. (2007), "O Senado e as aprovações de autoridades: um estudo comparativo entre Argentina e Brasil". Revista Brasileira de Ciências Sociais, 22 (64): 115-138.

LEMOS, Leany \& RANINCHESKI, Sônia. (2003), "Carreras políticas en el Senado brasileño: un estudio de las composiciones del Pleno y de las Comisiones de Constitución, Justicia y Ciudadanía en la década del 90". Lateinamerika Analysen, 4: 3-30.

LIJPHART, A. (1999), Patterns of democracy: go- vernment forms and performance in Thirty-Six Countries. New Haven, Yale University Press.

LLANOS, Mariana \& NOLTE, Detlef. (2003), "Bicameralism in the Americas: around the extremes of symmetry and incongruence". The Journal of Legislative Studies, 9 (3): 54-86.

LOOSEMORE, J. \& HANBY, V. (1971), “The theoretical limits of maximum distortion: some analytic expressions for electoral systems". British Journal of Political Scienc, 1 (4): 467-477.

LOUREIRO, Maria Rita. (2001), "O Senado no Brasil recente: política e ajuste fiscal”. São Paulo em Perspectiva, 15: 53-61.

LOUREIRO, Maria Rita \& ABRUCIO, Fernando. (2004), "Política e reformas fiscais no Brasil recente". Revista de Economia Política, 24 (1): 50-72.

MAINWARING, Scott. (2001), Sistemas partidários em novas democracias: o caso do Brasil. Porto Alegre, FGV/Mercado Aberto.

MAINWARING, Scott \& PÉREZ-LIÑAN, Anibal. (1997), "Party discipline in the Brazilian constitutional congress". Legislative Studies Quarterly, 22 (4): 453-483.

MAINWARING, Scott \& SHUGART, Matthew. (1997), Presidentialism and democracy in Latin America. Cambridge, Cambridge University Press.

MASSICOTTE, L. (2001), "Legislative unicameralism: a global survey and a few case studies". Journal of Legislative Studies, 7 (1): 151-170.

MENEGUELLO, Rachel. (1998), Partidos e governos no Brasil contemporâneo. Rio de Janeiro, Paz e Terra.

NEIVA, Pedro. (2006), "Os determinantes da existência e dos poderes das câmaras altas: federalismo ou presidencialismo?”. Dados, 49 (2): 269-299.

(2008), "Women in upper houses: a global perspective”. Brazilian Political Science Review, 3 (online).

- (2011A), "Disciplina partidária e apoio ao governo no bicameralismo brasileiro". Revista de Sociologia e Política, 19 (39): 17-30.

(2011B), "Coesão e disciplina partidária no Senado Federal”. Dados, 54 (2): 289-318. 
NEIVA, Pedro \& IZUMI, Maurício. (2012a), “Os 'doutores' da federação: formação acadêmica dos senadores brasileiros e variáveis associadas". Revista de Sociologia e Política, 19 (39): 171-192.

NEIVA, Pedro \& IZUMI, Maurício. (2012b), “Os sem-votos do Legislativo brasileiro: quem são os senadores suplentes e quais os seus impactos sobre o processo legislativo". Opinião Pública, 18 (1): 1-21.

PALERMO, Vicente. (2000), "Como se governa o Brasil? O debate sobre instituições políticas e gestão de governo". Dados, 43 (3): 35-57.

PATTERSON, S. \& MUGHAN, A. (2001), "Fundamentals of institutional design: the functions and powers of parliamentary second chambers". Journal of Legislative Studies, 7 (1): 39-60.

PEREIRA, Carlos \& RENNÓ, Lúcio (2001). "O que é que o reeleito tem? Dinâmicas político-institucionais locais e nacionais nas eleiçôes de 1998 para a Câmara dos Deputados.” Dados, 44 (2): 133-172.

RICCI, Paolo. (2008), “A produção legislativa de iniciativa parlamentar no Congresso brasileiro: diferenças e similaridades entre a Câmara dos Deputados e o Senado federal", in Leany Lemos (org.), O Senado federal brasileiro no pós-Constituinte. Brasília, Editora do Senado Federal, pp. 237-271.

RIKER, William. (1964), Federalism: origin, operation, significance. Boston, Little, Brown.

RUSSELL, M. (2001), "What are second chambers for?”. Parliamentary Affairs, 54 (3): 442-458.

SAMUELS, David. (2003), Ambitiom, federalism, and legislative politics in Brazil. Cambridge, Cambridge University Press.

(2008), "The gubernatorial coattails effect: federalism and congressional elections in Brazil". The Journal of Politics, 62 (1): 240-253.

SAMUELS, David \& ABRUCIO, Fernando. (2000), "Federalism and democratic transitions: the 'new' politics of the governors in Brazil". Publius: The Journal of Federalism, 30 (2): 43-61.

SAMUELS, David \& SNYDER, Richard. (2001),
"The value of a vote: malapportionment in comparative perspective". British Journal of Political Science, 31 (4): 651-671.

SANTOS, Wanderley Guilherme dos (1987). Crime e castigo: partidos e generais na política brasileira. Rio de Janeiro, Vértice.

SELCHER, Wayne. (1998), "The politics of decentralized federalism, national diversification, and regionalism in Brazil". Journal of Inter-American Studies and World Affairs, 40 (4): 25-50.

SOARES, Gláucio. (2001), A democracia interrompida. Rio de Janeiro, FGV.

SOARES, Márcia (2007). Democracia, representação política e federalismo no Brasil. Rio de Janeiro, tese de doutorado, Iuperj.

SOARES, Márcia \& LOURENÇO, Luiz. (2004), "A representação política dos estados na federação brasileira". Revista Brasileira de Ciências Sociais, 19 (56): 113-154.

SOARES, Márcia \& NEIVA, Pedro. (2011), "Federalism and resources publics in Brazil: discretionary transfers to States". Brazilian Political Science Review, 5 (2): 94-116 (online).

SOUZA, Celina. (1998), "Intermediação de interesses regionais no Brasil: o impacto do federalismo e da descentralização". Dados, 41 (3): 569-591.

SOUZA, Maria Carmo Campelo. (1976), Estado e partidos políticos no Brasil (1930-1964). São Paulo, Alfa-Ômega.

STEPAN, A. (1999), "Para uma nova análise comparativa do federalismo e da democracia: federaçôes que restringem ou ampliam o poder do Demos”. Dados, 42 (1): 593-634.

(2000), "Brazil's decentralized federalism: bringing government closer to the citizens?”. Daedalus, 129 (2): 145-169.

(2001), Arguing comparative politics. Oxford, Oxford University Press.

SWENDEN, Wilfried. (2011), "Subnational participation in national decisions: the role of second chambers", in H. Ederlein, S. Walti e M. Zurn (eds.), Handbook on multi-level governance. Northampton, Edward Elgar Publishing, pp. $103-123$

TOCQUEVILLE, Alexis de. (2003), Democracy in 
America. Washington, Regnery Publishing Inc. TSEBELIS, George \& MONEY, Jeanette. (1997), Bicameralism. Cambridge, Cambridge University Press.

VILAROUCA, Márcio. (2006), “Taxa de sucesso legislativo do Executivo no processo bicameral: comparando os governos FHC e Lula (19952006)". Rio de Janeiro, tese de doutorado, Iuperj.

WILLIS, Elisa; GARMAN, Christopher \& HAGGARD, Stephen. (1999), "The politics of decentralization in Latin America". Latin American Research Review, 34 (1): 7-56. 


\section{SENADO BRASILEIRO: CASA FEDERATIVA OU PARTIDÁRIA?}

Pedro Robson Pereira Neiva e Márcia Miranda Soares

Palavras-chave: Senado; Governadores; Legislativo; Partidos; Federalismo.

Esse artigo busca compreender as decisões tomadas pelos senadores brasileiros em votações nominais no plenário do Senado. Especificamente, avalia se os governadores influenciam os votos dados pelos senadores dos seus respectivos estados, tanto em matérias de interesse geral quanto nas matérias de caráter federativo. Para isso, controlamos o efeito de outras variáveis supostamente importantes para explicá-los Verificamos que os governadores não se apresentaram como atores de veto às políticas nacionais. Ao contrário, os resultados encontrados reforçam os argumentos da literatura que tem prevalecido ultimamente, a qual afirma que a força dos partidos políticos e do poder Executivo é capaz de promover a tomada de decisão no Congresso e a aprovação de uma agenda de caráter nacional.

\section{THE BRAZILIAN SENATE: A FEDERATIVE OR A PARTY POLITICS CHAMBER?}

Pedro Robson Pereira Neiva and Márcia Miranda Soares

Keywords: Senate; State governor; Legislature; Political parties; Federalism.

The article seeks to understand the decisions made by Brazilian senators in processes of nominal voting at the Senate floor. Specifically, it assesses whether state governors influence the votes cast by the senators of their respective states, both in matters of general interest as in those of federative character. For such assessment, the research controlled the effect of other variables supposed important in explaining the senators' votes. One of its outcomes is the verification that state governors were not veto players in matters of national policies. On the contrary, the results found reinforce the arguments lately prevailing in the literature, which asserts that the strength of the political parties and the executive branch is able to promote the decision-making in Congress and the approval of an agenda of national character.

\section{LE SÉNAT BRÉSILIEN : INSTANCE FÉDÉRATIVE OU PARTISANE?}

\section{Pedro Robson Pereira Neiva et Márcia} Miranda Soares

Mots-clés: Sénat; Gouverneurs; Législatif; Partis politiques; Fédéralisme.

Cet article cherche à comprendre les décisions prises par les sénateurs brésiliens en votes nominatifs dans l'enceinte du Sénat. Il évalue, en particulier, si les gouverneurs influencent les votes exprimés par les sénateurs de leurs États respectifs, aussi bien en ce qui concerne les sujets d'intérêt général que ceux de caractère fédéral. Pour cela, nous contrôlons l'effet d'autres variables soi-disant importantes pour les expliquer. Nous avons constaté que les gouverneurs ne se sont pas présentés comme des acteurs de veto aux politiques nationales. Au contraire, les résultats rencontrés renforcent les arguments de la littérature qui a prévalu dernièrement, qui affirme que la force des partis politiques et du Pouvoir Exécutif est en mesure de promouvoir la prise de décisions au Congrès et l'approbation d'un programme de caractère national. 